EESTI NSV TEADUSTE AKADEEMIA TOIMETISED. 20. KOIDE

KEEMIA * GEOLOOGIA. 1971, NR. 2

ИЗВЕСТИЯ АКАДЕМНИ НАУК ЭСТОНСКОИ ССР. ТОМ 20

ХИМИЯ $=$ ГЕОЛОГМЯ. 1971 , № 2

удК $551,491.4(474,2)$

AINO PILI

\title{
MEREVEE MÕJU PINNASEVEE KEEMILISELE KOOSTISELE EESTI NSV EDELARANNIKUL
}

Kui lähtuda I. Garmonovi (Гармонов, 1948) poolt eristatud pinnaser'ee* vööndeist, siis kuulub Eesti oma looduslike tingimuste poolest vesinikkarbonaatse kaltsiumilise vee vööndisse. Selles vööndis moodustub pinnasevesi sademete infiltratsiooni teel ning tema keemiline koostis kujuneb mulla ja kivimite leostumise tulemusena. Niisuguse vee mineralisatsioon on văike ja vesi kuulub vesinikkarbonaatsesse magneesiumilis-kaltsiumilisse hüdrokeemilisse tüüpi. Lokaalselt esineb aga mitmeid tegureid, mis muudavad selle vööndi pinnasevee keemilist koostist ja mineralisatsiooni. Uheks selliseks teguriks on merevesi, mis pinnaseveega kokku puutudes mõjutab viimase keemilist koostist.

Aastail 1967-1968 uuris autor pinnasevee keemilist koostist Eesti NSV edelarannikul Pärnust Iklani 2,5-3 km laiusel rannikuribal, mille mandripoolseks piiriks olid rannikuga paralleelselt kulgevad luiteahelikud. Uuritud rannikuriba (joon. 1) asub Pärnu madalmiku lounaosas $0-4 \mathrm{~m}$ absolluutsel kõrgusel. Enamasti langeb siin maapind aeglaselt mere poole (kalle kuni $1 \mathrm{~m} / \mathrm{km}$ ), kohati aga, nagu Tahku, Viira, Kura jt. külade juures, tõuseb maapind juba rannast $100-$ $200 \mathrm{~m}$ kaugusel $1-2 \mathrm{~m}$ üle merepinna (joon. 2). Pinnas koosneb kõnesoleval rannikuribal kobedatest kvaternaarsetest setetest, mis kuuluvad holotseeni ja pleistotseeni. Aluspõhjaks neile on devoniajastu pärnu, naroova või aruküla lademe settekivimid. Kvaternaarsete setete koostis on siin väga vahelduv nii horisontaalses kui ka vertikaalses suunas. Setete paksus rannikuriba pōhjapoolses osas kuni Treimanini kõigub

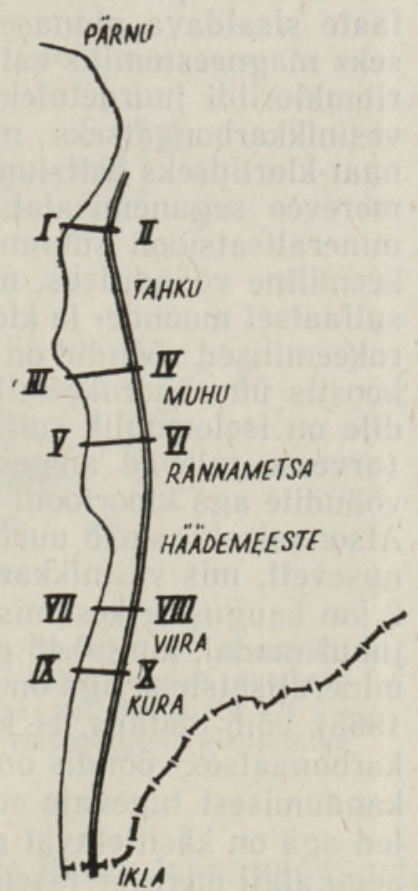

Joon. 1. Uuritud rannikuala skemaatiline plaan. Rooma numbrite paaridega on märgitud hüdrogeoloogiliste profiilide kohad.

* Pinnasevesi on vabapinnaline pōhjavesi, mis maapinnalt arvates asub esimeses pidevalt eksisteerivas veehorisondis esimesel vettpidaval kihil (Овчинников, 1954). 
1,5-5 m piires, siit lõuna poole ulatub see $30 \mathrm{~m}$-ni, Treimani ürgorus aga isegi üle $120 \mathrm{~m}$. Need setted pole kogu läbilôike ulatuses vettkandvad. Savikad erimid moodustavad suhteliselt vettpidavaid kihte, mistôttu nende all paiknevates alumistes liivakas-kruusakates setetes esinev vesi on surveline. Pinnasevett sisaldavaiks setteiks on peene- kuni keskmiseteralised kohati kruusvahekihtidega liivad ja aleuriidid. Vettpidava lamami moodustavad enamasti viirsavid, devoni savikad setted ja savikas moreen. Kohati lamavad kvaternaarsete kobedate setete all devoni vettsisaldavad liivakivid. Neis paigus on kvaternaarsete setete vesi hüdrauliliselt seotud alam-tartu või pärnu-naroova veehorisondi veega.

Pinnasevee keemilise koostise uurimiseks võeti veeproove kaevudest, mis asetsesid enam-vähem ühel, rannaga risti kulgeval joonel. Analüüsidetulemused (arvestatavaid 77) andsid üsna kirju pildi. Kui pinnasevesi meie territooriumil on enamasti vesinikkarbonaatne magneesiumilis-kaltsiumiline või kaltsiumilis-magneesiumiline mineralisatsiooniga $0,3-0,5 \mathrm{~g} / \mathrm{l}$, liivaaladel kohati 0,1-0,2 g/1 (Верте, 1965; Қаризе, 1966), nagu sellisele pinnasevee vööndile on omane, siis vaadeldaval rannikuribal on sageli. kõigi kuue olulise komponendi (anioonidest vesinikkarbonaat, sulfaat ja kloor, katioonidest kaltsium, magneesium ja naatrium + kaalium) sisaldus. pinnasevees üle 20 ekv.- $\%$, mineralisatsioon aga tõuseb kohati $3 \mathrm{~g} / 1$. Seejuures võib rannikule lähenemisel täheldada pinnasevee keemilise tüübi muutumisel teatud seaduspärasust. A. Verte (Верте, 1965) järgi muutub. mandrilt mere poole liikuv vesinikkarbonaatne teatud hulgal sulfaate sisaldav surveta pinnasevesi rannikul merevee poolt mõjutatud ja samuti sulfaate sisaldava pinnaseveega kohtudes alguses sulfaat-vesinikkarbonaatseks magneesiumilis-kaltsiumiliseks, seejärel aga ranna lähedal, kus naatriumkloriidi juurdetulek mereveest difusiooni teel on intensiivne, kloriidvesinikkarbonaatseks magneesiumilis-naatriumiliseks, siis vesinikkarbonaat-kloriidseks kaltsiumilis-naatriumiliseks ja päris rannas, pinnasevee ja. merevee segunemisalal, soolakaks kloriidseks naatriumiliseks, kusjuures. mineralisatsioon suureneb. Nii moodustub rannikul horisontaalne hüdrokeemiline vööndilisus, milles anioonse koostise järgi on võimalik eristada sulfaatset moonde- ja kloriidset segunemisvööndit. Üldjoontes taolised hüdrokeemilised vööndid on eristatavad ka kõnesoleval rannikul. Vee keemiline koostis ühe hüdrokeemilise vööndi vlatuses pole püsiv. Sulfaatsele vööndile on iseloomulik sulfaationni esinemine kas teisel või kolmandal kohal (arvesse tulevad anioonid, mida vees leidub üle 20 ekv. $\%$ ), kloriidselevööndile aga klooriooni esinemine esimesel või teisel kohal anioonide seas. Atsonaalselt esineb uuritud alal kloriid-vesinikkarbonaatse koostisega pinnasevett, mis vesinikkarbonaatse vee esinemisalal laiguti on levinud kuni $2 \mathrm{~km}$ kaugusele keskmisest rannajoonest (tab. 1). Mineralisatsioon on sel juhul madal, kuni $0,45 \mathrm{~g} / \mathrm{l}$, kloriidse vööndi kloriid-vesinikkarbonaatse vee mineralisatsioon aga on üle $0,8 \mathrm{~g} / \mathrm{l}$. Kirjanduse andmete alusel (Стремякоз, 1965) võib oletada, et kloori ja naatriumi suhteline suurenemine vesinikkarbonaatses vööndis on suhteliselt lagedal alal tingitud merevee osakeste kandumisest tugevate edelatuultega paari kilomeetri kaugusele. Edelatuuled aga on käsitletaval alal valitsevaiks ja tugevate tuultega kaasneb peaaegu alati merevee taseme tõus. Samuti võivad pinnasevett rannikul kloriidide ja naatriumiga rikastada sademed (Верте, 1965).

Sulfaatses vööndis mere poole liikuv pinnasevesi rikastub keerulistefüüsikalis-keemiliste protsesside toimel sulfaatidega, mille tulemusena muutub tema hüdrokeemiline tüüp. Mida peeneteralisemad on vett sisaldavad setted ja mida väiksem on hüdrauliline kalle, seda soodsamad vōimaJused on nende protsesside kulgemiseks ja seda laiem on sulfaatne vöönd. Kloriidses vööndis sõltub vee keemiline tüüp sellest, kas segunemisel oli 
ülekaalus merevesi või sulfaatsest vööndist mere poole liikuv pinnasevesi. Ka selle vööndi laiıs oleneb setete koostisest ja maapinna langusest. Maapinna kiire languse (pinnasevee hüdrauliline kalle suurem kui 0,001) ja heade filtratsiooniliste omadustega setete puhul (filtratsioonimoodul 15$20 \mathrm{~m} /$ öop.) on pinnasevee juurdevool mandri poolt tugev ning piirab merevee mõju ulatust mandrisetetes. Sellest tingituna moodustuvad kitsad hüdrokeemilised vööndid. Niisugused vööndid esinevad uuritud alal lõuna pool Häädemeestet, kus luiteahelikud lähenevad rannale, ahendades mere ja luidete vahelist ala. Maapınna langus on siin suhteliselt kiirem ja pinnasevee hüdrauliline kalle suurem (joon. 2).
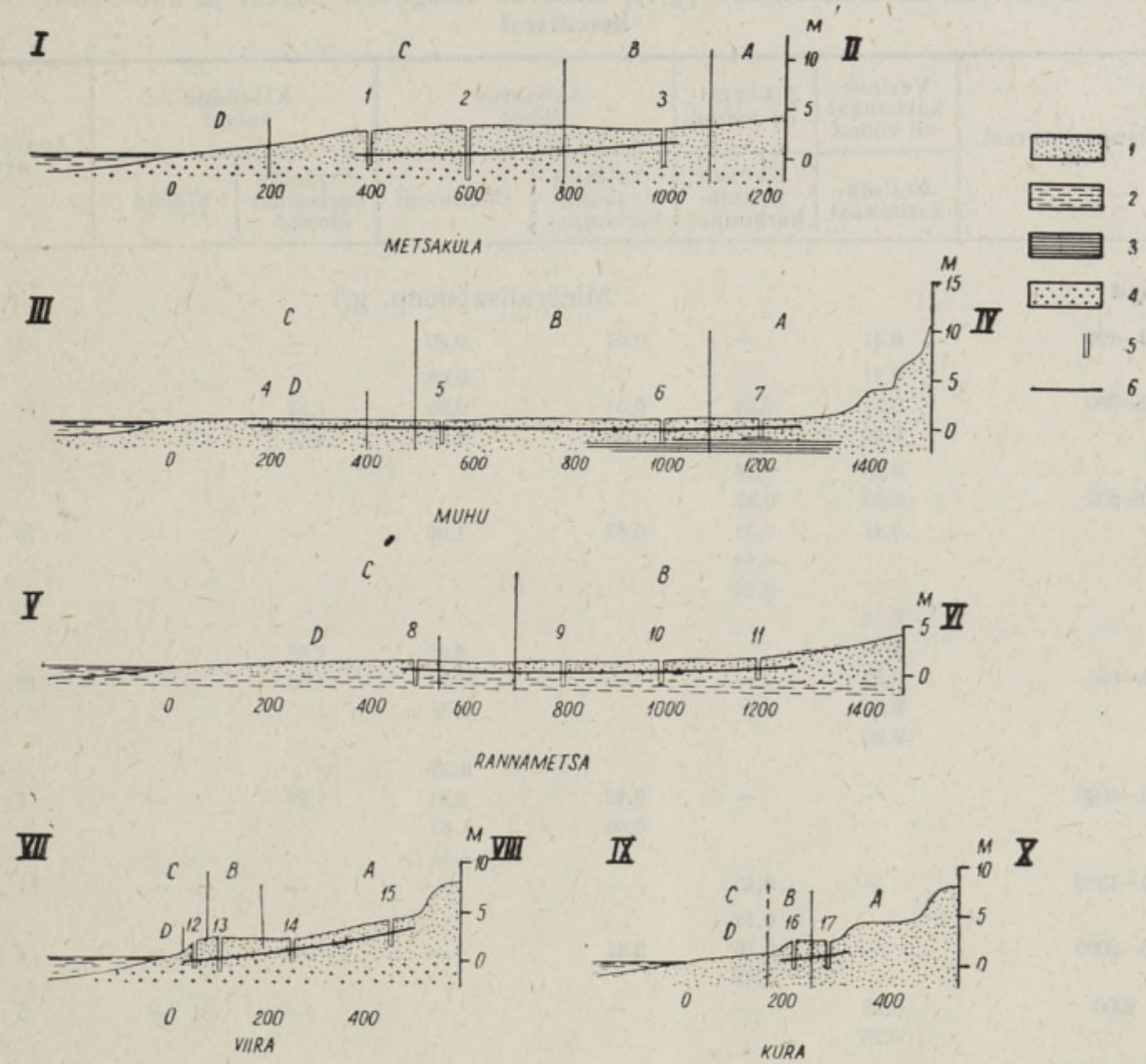

Joon. 2. Skemaatilised hüdrogeoloogilised profiilid: 1 - liivad; $2-$ aleuriidid; 3 - viirsavid; 4 - liivakivid; 5 - kaev, number kaevu kohal vastab numbrile tabelis $2 ; 6-$ pinnasevee tase; $A-$ vesinikkarbonaatse vee levikuala; $B-$ sulfaatne vöönd; $C$ - kloriidne vöönd; $D$ - ajuveega episoodiliselt üleujutatav ala.

Merevee mõju pinnasevee keemilisele koostisele Pärnu lahe rannas on uurinud A. Silin-Bektšurin (Силин-Бекчурин, 1958). Ta tegi kindlaks, et $2 \mathrm{~km}$ kaugusel rannast on pinnasevee mineralisatsioon $0,5 \mathrm{~g} / 1$, kloorioonisisaldus ei ületa $20 \mathrm{mg} / \mathrm{l}$, sulfaadid puuduvad. Rannale lähenemisel kloorioonide hulk suureneb $(200 \mathrm{mg} / \mathrm{l})$ ja tõuseb järsult mere ääres (400$500 \mathrm{mg} / \mathrm{l})$. Pinnasevee soolastumine on A. Silin-Bektšurini arvates tingitud merevee taseme tõusu tagajärjel korduvalt üleujutatud rannasetetesse filtreerunud soolasest veest. Ilmselt on ta sellisele järeldusele tulnud pro- 
fiilidelt liiga harvalt võetud proovide aiusel. Käesolevad uurimised näitasid, et kloorioonide hulk tõuseb kohati $800 \mathrm{~m}$, aleuriitides aga juba $1000 \mathrm{~m}$ kaugusel rannast $500 \mathrm{mg} / \mathrm{l}$, kohati aga on $100-150 \mathrm{~m}$ kaugusel rannast kloriide vees vaid $14-23 \mathrm{mg} / \mathrm{l}$, mida ei saa seletada ainuüksi A. SilinBektšurini poolt esitatud pinnasevee soolastumise mehhanismiga. Riia ja Pärnu lahes ei esine tõusu-mõõna, tuultest tingitud ajuvesi aga ulatub lauge ranniku tõttu keskmisest rannajocnest kuni $500 \mathrm{~m}$ kaugusele mand-

Tabel 1

Pinnasevee mineralisatsioon $(\mathrm{g} / \mathrm{l})$, olenevalt kaugusest merest ja anioonsest koostisest

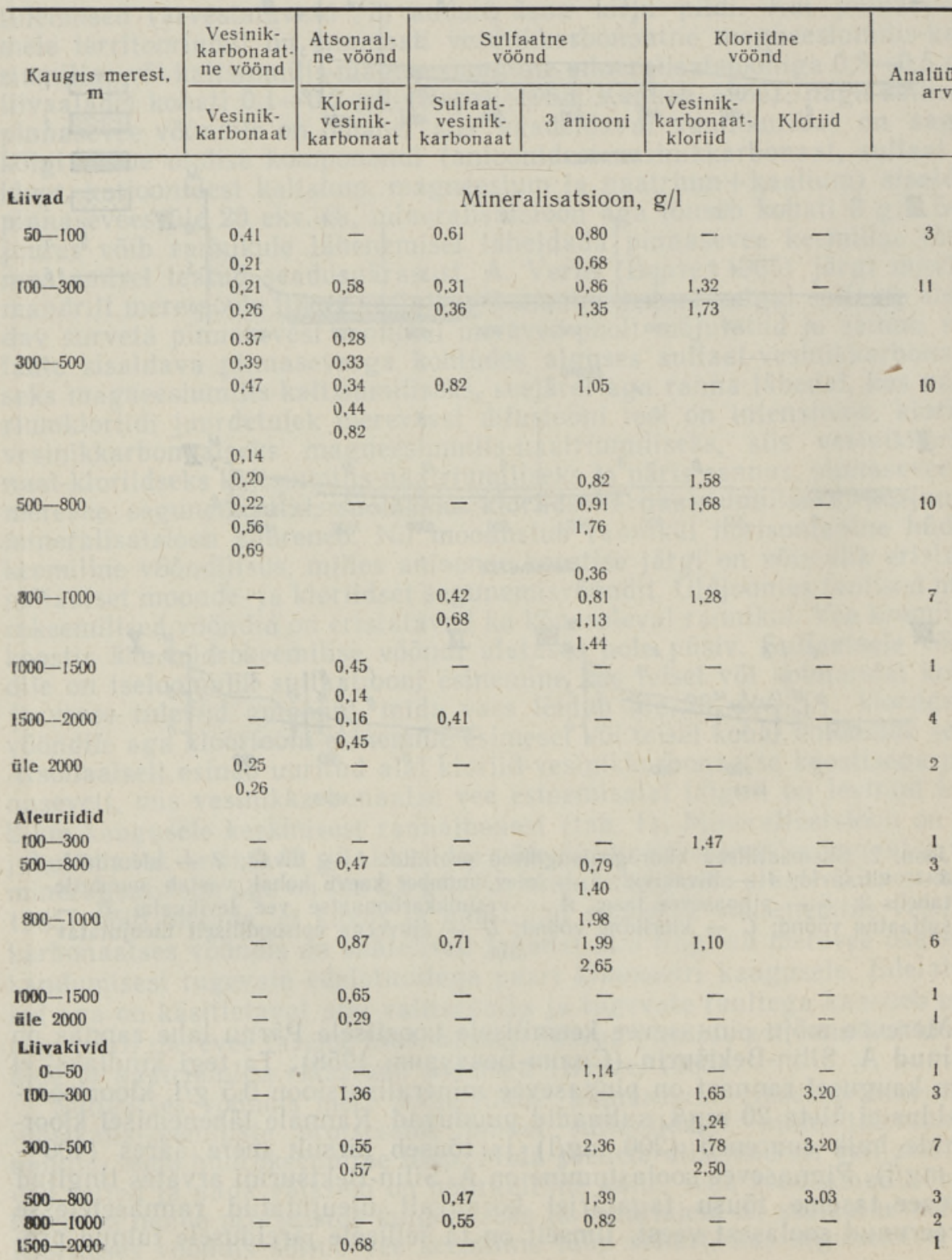




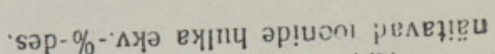

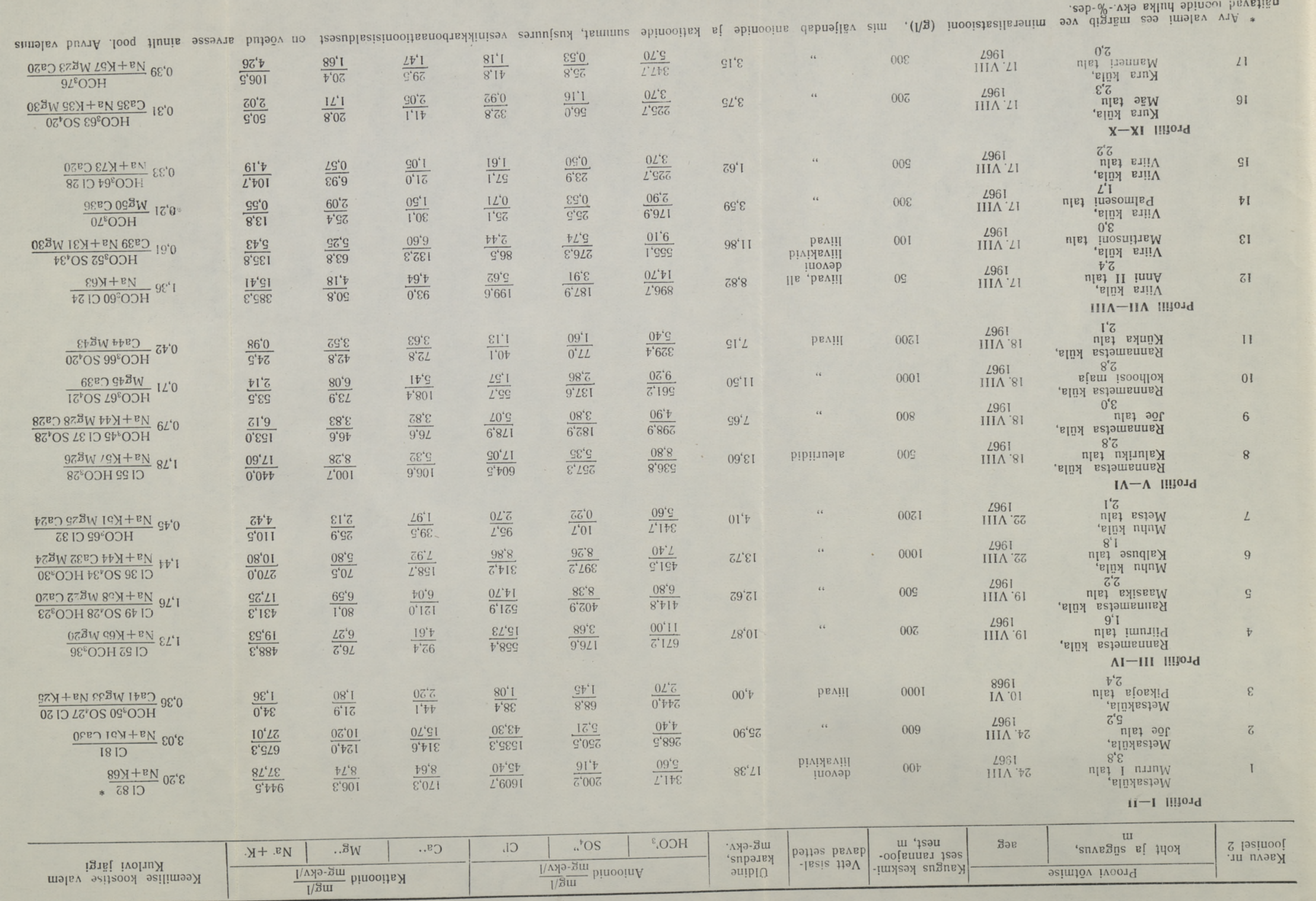


rile. Suuri üleujutusi esineb harva, kord $20-30$ aasta jooksul, ja nende kestus on lühiajaline. Peamiseks, mis muudab rannikul pinnasevee keemilist koostist, on nähtavasti siiski filtratsiooniline difusioon, millega kaasneb osmoos, katioonide ja anioonicie vahetus, mõnede soolade väljalangemine jne. (Scheidegger, 1960; Николаевский, 1960; Шестаков, 1961; Бабушкин jt., 1969).

Tabelis 1 on esitatud andmed pinnasevee mineralisatsiooni mutuste kohta erinevais setetes, olenevalt kaevu kaugusest merest ja vee anioonsest koostisest. Selgub, et vesinikkarbonaatset yett esineb uuritud alal ainult liivades. See ei tähenda, et keskmisest rannajoonest $1,5-2,0 \mathrm{~km}$ kaugusel olevates devoni setetes sellise koostisega pinnasevesi puuduks, kuna see aga lasub sügaval, siis teda ei kasutata. Vesinikkarbonaatse vee mineralisatsioon kõigub $0,14-0,70 \mathrm{~g} / \mathrm{l}$, kusjuures suurema hüdraulilise kaldega aladel Iklast Häädemeesteni on mineralisatsioon $0,14-0,22 \mathrm{~g} / \mathrm{l}$. Lauge reljeefiga Pulgoja ja Rannametsa külas, kus pinnasevee voolukiirus ei ületa $0,01-0,02 \mathrm{~m} /$ ööp., on vee mineralisatsioon kuni $0,7 \mathrm{~g} / \mathrm{l}$. Siin ulatub vesinikkarbonaatne vesi ainult $0,5-1 \mathrm{~km}$ kaugusele rannast, Ikla-Häädemeeste vahel aga on ta vaid $100-150 \mathrm{~m}$ kaugusel rannast. Katioonidest esinevad enamasti kõik kolm, kusjuures esikoht kuulub peaaegu alati kaltsiumile. Séega on vesi oma keemiliselt tüübilt vesinikkarbonaatne magneesiumilis-kaltsiumiline või magneesiumilis-naatriumilis-kaltsiumiline.

Edasi mere poole tõuseb sulfaatide absoluutne sisaldus pinnasevees ning nende suhteline hulk ületab 20 ekv.- $\%$, sulfaadid aga asuvad anioonide hulgas arvestatavale teisele või kolmandale kohale. Nagu tabelist 1 näha, on sulfaat-vesinikkarbonaatse vee mineralisatsioon madalam. Siin on see keskmiselt $0,4-0,7 \mathrm{~g} / \mathrm{l}$, kolme aniooni puhul $0,7-1,0 \mathrm{~g} / \mathrm{l}$, sageli aga ületab $1,0 \mathrm{~g} / \mathrm{l}$. Kõige madalama mineralisatsiooniga on pinnasevesi selles vööndis lõuna pool Häädemeestet. 150-200 m kaugusel keskmisest rannajoonest on mineralisatsioon vaid $0,31-0,36 \mathrm{~g} / 1$ (tab. 2). Sulfaat-vesinikkarbonaatne pinnasevesi on rohkem vööndi mandripoolse piiri läheduses, vee mere poole liikudes lisandub talle kloori, tänu sellele tõuseb ka mineralisatsioon. Sulfaatse vööndi laius kõigub Ikla-Häädemeeste vahel $50-$ i00 m-ni, Häädemeestest Pärnu poole aga 0,2-0,8 km-ni. Merepoolne piir asub keskmisest rannajoonest $0,05-0,8$, mandripoolne $0,2-1,2 \mathrm{~km}$ kaugusel. Katioonidest esinevad enamasti kõik kolm, kusjuures igaüht neist on üle 20 ekv.- \%. Mandripoolses osas domineerib kaltsium, mere poole suureneb naatriumi hulk ja muutub katioonidest prevaleerivaks. Magneesium püsib teisel või kolmandal kohal. Pinnasevee hüdrokeemilistest tüüpidest on sulfaatses vööndis levinumad sulfaat-vesinikkarbonaatne naatriumilis-kaltsiumiline, sulfaat-kloriid-vesinikkarbonaatne või vesinikkarbonaat-sulfaat-kloriidne naatriumilis-magneesiumilis-kaltsiumiline või kaltsiumilis-magneesiumilis-naatriumiline (tab. 2).

Veelgi edasi mere poole suureneb kloori ja naatriumi hulk, sulfaatidesisaldus aga langeb alla 20 ekv.- \%. Devoni kivimite vees muutub kloor anioonide seas isegi ainuvalitsevaks. Pinnasevee mineralisatsioon kõigub $1,2-1,7 \mathrm{~g} / \mathrm{l}$. Ainult devoni setetes esineva kloriidse natriumilise vee mineralisatsioon ületab $3 \mathrm{~g} / \mathrm{l}$. Domineerivaks katiooniks on naatrium, mis katioonidest moodustab vähemalt 50 ekv.-\%. Magneesiumi- ja kaltsiumisisaldus kõigub 20-30 ekv.- \% vahel. Sageli esineb neist ainult üks, kuid ka siis ei ületa tema sisaldus 30 ekv.- \% katioonidest. Hüdrokeemiliselt tüübilt on veși enamasti vesinikkarbonaat-kloriidne kaltsiumilis- või magneesiumilis-naatriumiline või magneesiumilis-kaltsiumilis-naatriumiline. Devoni kivimeis esinevast veest toituvates kaevudes on vesi kloriidne naatriumiline. Vööndi mandripoolne piir kulgeb $0,05-0,8 \mathrm{~km}$ kaugusel keskmisest veepiirist, merepoolseks aga on keskmine veepiir. Reljeefi suhteliselt 
suure languse korral langeb kloriidne vöönd ilmselt kokku alaga, mida ajuvesi episoodiliselt üle ujutab.

Eeltoodust ilmneb, et merevesi ei mõju pinnasevee keemilisele koostisele soodsalt. Tema mõjul muutub pinnasevee keemiline koostis ja maitselised omadused. Rannaäärsete talundite kaevudes on vesi kare, mineralisatsioon kõrge, ületades sageli normatiivse $1 \mathrm{~g} / \mathrm{l}$. Rohke kloriidide- ja naatriumisisalduse korral on vesi soolakas, mistõttu elanikud kasutavad majapidamiseks sageli kuivenduskraavidest võetud madala mineralisatsiooniga $(0,16-0,17 \mathrm{~g} / \mathrm{l})$ sulfaat-vesinikkarbonaatset magneesiumilis-kaltsiumilist tüüpi vett (Pikla küla), mis tegelikult on luiteliivadest valgunud pinnasevesi.

\section{K I R JANDUS}

Scheidegger A. E. 1960. Growths of instabilities on displacement fronts in porous media. J. Phys. Fluids, 3, No. 1.

Ба бушкин В. Д., Глазунов И. С., Гольдберг В. М., Пичугин Н. И., Ш а вырин а А. В. 1969. Поиски, разведка, оценка запасов и эксплуатация линз пресных вод. М.

В е р т е А. Я. 1965. Основные черты гидрогеологического строения и формировання подземных вод Эстонского артезианского бассейна. Изв. АН ЭССР. Биол., 14, № 4.

Г арм онов И. В. 1948. Зональность грунтовых вод Европейской части СССР. Тр. лаб. гидрогеол. проблем, III.

К ар и з е В. Ю. 1966. Основные черты формирования состава вод четвертичных отложений Южной Эстонии. Изв. АН ЭССР, Сер. фнз.-матем. и техн. н., 15, № 4.

Н и кол а е в ски й В. Н. 1960. Некоторые задачи распространения меченых частиц в фильтрационных потоках. Изв. АН СССР, Отд. мех. и машиностр., № 5.

О в ч и н н и о в А. M. 1954. Общая гидрогеология. M.

С илин - Бек ч урин А. И. 1958. Гидродинамические и гидрохимические закономерности на территорни Прибалтики. Тр. лаб. гидрогеол. проблем. $\mathbf{X X .}$

С тремя ков А. Я. 1965. Особенности формирования состава грунтовых и поверхностных вод Чукотского полуострова. Гидрохим. мат-лы, XXXIX.

Ш е с таков В. М. 1961. Фильтрация из хранилищ промышленных стоков. М.

\section{Eesti NSV Teaduste Akadeemia Geoloogia Instituut}

Toimetusse saabunud 18. I 1971

\section{АННО ПИЛЛЬ}

\section{ВЛИЯНИЕ МОРСКОИ ВОДЫ НА ХИМИЧЕСКИИ СОСТАВ ГРУНТОВЫХ ВОД У ЮГО-ЗАПАДНОГО ПОБЕРЕЖЬЯ ЭСТОНСКОИ ССР}

Распространенные на территории Эстонии грунтовые воды имеют минерализацию $0,3-0,52 / \Omega$ (в песках иногда $0,1-0,2$ z/л) и по своему химическому составу относятся к гидрокарбонатному магниево-кальциевому типу. Однако существует целый ряд локальных факторов, влияющих на химический состав и минерализацию грунтовых вод. Одним нз них является морская вода.

В 1967-1968 годах автором исследовалось влияние морской воды на химический состав грунтовых вод у побережья Рижского залива, от r. Пярну до пос. Икла (см. рис. 1). Установлено, что там, где солоноватая морская вода контактирует с пресными грунтовыми водами, образуется горизонтальная гидрохимическая зональность. По изменению анионного состава выделяются зона смешения (или хлоридная зона) и зона метаморфизации (или сульфатная зона). Далее, в сторону суши, распространена гидрокарбонатная вода. Характерно, что в сульфатной зоне по содержанию анионов сульфатион стоит на втором или третьем месте (в расчет принимались анноны, присутствовавшие в количестве более 20 экв. \%), а в хлоридной зоне хлор-ион - на первом или втором месте.

В табл. 1 показано изменение общей минерализации грунтовых вод в различных водовмещающих породах в зависимости от аннонного состава и расстояния места опробования от средней береговой линии. Видно, что минерализация гидрокарбонатной воды, вообще говоря, низкая. Из катиснов преобладает кальций (см. табл. 2). Местами 
в области распространения гидрокаробонатной воды встречается хлоридно-гидрокарбонатная вода. Здесь минерализация ее тоже низкая, в то время как в хлоридной зоне она выше. Из катионов преобладает натрий. В сульфатной зоне минерализация воды, содержащейся в алевритах и песчаниках, выше, чем в песках. Минерализация в целом повышается в сторону хлоридной зоны, где встречаются различные гидрохимические тнпы воды (см. табл. 2). В хлоридной зоне возрастает содержание хлор-ионов и уменьшается количество сульфат-но!ов, при этом минерализация превышает 1 2/ $\Omega$, а в песчаниках достигает 3 2/л. Из катионов преобладает натрий. Севернее пос. Хяэдемээсте ширина сульфатной зоны достигает $0,2-0,8 \kappa м$, а хлоридной - 0,4-0,8 км. K югу ширина этих зон уменьшается до нескольких десятков метров, что, по нашему мнению, зависит от гранулометрического состава водовмещающих пород н гидравлического уклона подземных вод.

\section{AINO PILL}

\section{THE EFFECT OF SEA-WATER UPON THE CHEMICAL COMPOSITION OF THE GROUND-WATER ON THE SW COAST OF THE ESTONIAN SSR}

The degree of the mineralization of ground-waters on the territory of Soviet Estonia mostly amounts to $0.3-0.5 \mathrm{~g} / 1$ and in sandy areas - to $0.1-0.2 \mathrm{~g} / \mathrm{l}$. As to the chemical composition, they belong to the bicarbonaceous magnesian-calcarean type, but locally a number of factors may change the degree of mineralization and the chemical composition to a certain extent. Sea-water is one of those factors.

In 1967-1968, relevant researches along the coast of the Gulf of Riga, from Ikla to Pärnu, revealed that, in the contact areas of the saline sea-water with fresh groundwater, certain horizontal hydrochemical zones are formed, within the boundaries of which, according to the anionic composition (chloride, sulphate, bicarbonate), we may state a chloride and a sulphate zone. A typical feature of the sulphate zone is the occurrence of the sulphate ion either in the second or third place (here anions are considered, whose content is above $20 \mathrm{eq} \%$ ), whereas in the chloride zone the chloride ion occurs either in the first on second place, among the anions present. The sulphate zone situated north of Häädemeeste is $0.2-0.8 \mathrm{~km}$ wide, whereas the width of the chloride zone is $0.4-0.8 \mathrm{~km}$. South of Häädemeeste the width of the zones gradually decreases to a few dozen metres. 